\title{
A COESÃO SEMÂNTICA ENTRE AS LEXIAS RELACIONADAS AOS FATORES DE ATRIBUIÇÃO EM TEXTOS ACADÊMICOS DA ÁREA DE LETRAS E PSICOLOGIA
}

\author{
Cárla Callegaro Corrêa Kader ${ }^{1}$ \\ Marcos Gustavo Richter ${ }^{2}$
}

RESUMO: Este trabalho visa investigar a coesão semântica entre lexias relacionadas aos Fatores de Atribuição, previstos pela versão estendida da Teoria Holística da Atividade, em textos acadêmicos de Letras e Psicologia. Busca-se contrapor os resultados quantitativos do mapeamento semântico dos textos acadêmicos de uma profissão emancipada com os de uma profissão não emancipada. Para tanto, criou-se um corpus com textos acadêmicos da área de Letras e Psicologia. As lexias selecionadas são relacionadas ao campo de pesquisa da linguagem e profissionalização. O mapeamento semântico foi feito por meio de um software livre. Os resultados gerados por esse aplicativo foram inseridos em uma tabela e calculados de acordo com as orientações de Richter (2011). Os resultados demonstraram que os textos de Letras apresentam destaque quantitativo para as lexias que envolvem o conhecimento praxeológico em contraste com os textos de Psicologia que se destacaram quantitativamente em todas as subcategories dos Fatores de Atribuição.

Palavras-chave: Mapeamento Semântico; Fatores de Atribuição; Teoria Holística da Atividade.

ABSTRACT: This paper aims to investigate the semantic cohesion among words related to the Attribution Factors, previewed by the extended version of the Holistic Theory of Activity (THA), in Languages and Psychology academic texts. It is tried to compare the quantitative results of the semantic mapping between an emancipated profession to a non emancipated one. For this, it was created a corpus with academic texts in the area of Languages and Psychology. The selected words are related to the research field of language and professionalization. The semantic mapping was made by means of free software. The results generated by this applicative were inserted in a table and calculated according to the guidelines of Richter (2011).

\footnotetext{
${ }^{1}$ Doutoranda em Estudos Linguísticos pela Universidade Federal de Santa Maria (UFSM), bolsista do CNPQ, docente do Instituto Federal Farroupilha (IFFARROUPILHA). carlackader@gmail.com.

2 Professor Doutor do Programa de Pós-Graduação em Letras da Universidade Federal de Santa Maria (UFSM), orientador e coautor deste trabalho. richtermg@gmail.com.
} 
The results showed that the Language texts present a quantitative emphasis in the words that comprehend the praxeological knowledge in contrast to the Psychology texts which had a significant result in almost all subcategories of the Attribution Factor.

Keywords: Semantic Mapping; Attribution Factor; The Holistic Theory of Activity.

\section{INTRODUÇÃO}

Este trabalho visa investigar a coesão semântica entre as lexias relacionadas aos Fatores de Atribuição em textos acadêmicos de Letras e Psicologia. Busca-se contrapor os resultados quantitativos do mapeamento semântico dos textos acadêmicos de uma profissão emancipada como a Psicologia com os de uma profissão não emancipada como a de Letras. Para tanto, serão focalizadas as informações sobre o comportamento em rede semântica dos nódulos de interesse da área de Letras e Psicologia, observando os resultados do mapeamento com as lexias professor, profissional, formação, conhecimento, didática, motivação, ensino, precisa, deve e pode, dos corpora de estudo.

Esta pesquisa tem interesse em verificar as relações semânticas entre as lexias que representam os nódulos-problema e vínculo, e que estão relacionadas aos papéis sociais das profissões supracitadas, considerando os principais parâmetros dos Fatores de Atribuição, na Teoria Holística da Atividade $^{3}$ (THA) (RICHTER, 2008, 2011).

Conforme Richter e Garcia (2004), é o momento de repensar o papel do professor enquanto profissional, defini-lo enquanto ator no âmbito social, delimitar seu espaço de atuação, regulamentar deveres e direitos no exercício

\footnotetext{
${ }^{3}$ A THA considera central o conceito de papel social para caracterização do ecossistema social, formados por nichos semióticos habitados por membros de determinados grupos sociais. Esses nichos estão na dependência da inserção e interação de indivíduos. Cada sistema é resultante de escolhas humanas históricas, simultaneamente produto e processo, criada, institucionalizada e reinterpretada. Sistemas sociais são complexos, autorreferênciais e autopoiéticos, ou seja, o conhecimento construído e suas interpretações dependem de fatores históricos e estruturais intrínsecos a cada grupo, embora possa haver cisões, reorganizações e relações de conflitos e dominação-submissão intergrupos. A THA marca a situação extrínseca dos seres humanos em relação à linguagem como prática social. Parte-se da ideia de que sociedade e ser humano constituem tipos diferentes de sistemas, ao mesmo tempo disjuntos e acoplados, exercendo influência mútua incessante. Ela considera central o conceito de papel social para a caracterização dessa interface (RICHTER, 2011, p. 114).
} 
da profissão e criar condições objetivas para a educação no Brasil, a partir da questão da profissionalização do professor.

Neste estudo, busca-se contrapor o resultado do mapeamento semântico com lexias que representam as competências gnoseológica, praxeológica, ordenamento, necessidade e possibilidade que contemplam as regularidades atribucionais axiológicas, deônticas e epistêmico-aléticas, previstas na versão estendida da THA (RICHTER, 2011), em textos acadêmicos de Letras e Psicologia. Estas duas profissões são categorizadas como não regulamentadas e regulamentadas, respectivamente. A intenção da comparação dos resultados do mapeamento é demonstrar o nível de coesão semântica entre essas profissões, a fim de salientar a necessidade de regulamentação da profissão de educador linguístico.

Para Richter (2010), a comparação do educador, especificamente o linguístico, com outros profissionais habilitados, salienta a desarticulação entre intervenção profissional e expectativas de resultados (benefícios) a alcançar.

Segundo o autor, tanto as normas existentes quanto a realidade social exigem um tratamento mais rigoroso para o exercício da docência. Os profissionais dessa categoria carecem de uma regulamentação que thes ofereça, entre outras questões, condições para um trabalho de qualidade, socialmente valorizado e com retribuição pecuniária (RICHTER e GARCIA, 2004).

Destaca-se que não há leis específicas para regulamentar o trabalho do professor, assegurando o exercício autorizado apenas para profissionais devidamente habilitados, apesar da existência da legislação educacional brasileira com a Lei de Diretrizes e Bases da Educação Nacional (LDB n 9.394/96) e dos PCNs - Parâmetros Curriculares Nacionais ${ }^{4}$

Trata-se, nas palavras de Richter (2008, p. 9), de um "semiterritório", ou seja, não há no contexto da sociedade a designação de um conjunto de atribuições específicas, a saber: preceitos de ética corporativa que legitimem endogenamente a sua valorização.

\footnotetext{
${ }^{4}$ Tratam das questões de ensino.

${ }^{5}$ Grifo do autor.
} 
Isto se torna um problema, porque contribui para perpetuar mitos que distorcem o papel do professor na construção da cidadania. Para a categoria, implica tornar realidade a profissionalização efetiva por meio da sua maioridade, ou seja, da emancipação jurídica, a fim de proporcionar maior qualidade no exercício da profissão, não apenas em favor da classe, mas de todos que a ela recorrerem (RICHTER, 2010).

Essa afirmação pode ser confirmada em estudos anteriores de Richter (2011) sobre a profissionalização docente, segundo a Teoria Holística da Atividade, empregando software de mapeamento semântico. Esse autor investigou se o trabalho formativo socioconstrutivista, com primeiranistas de licenciatura em Letras, revela indícios discursivos da emergência de conceitos profissionalizantes sobre aquisição.

$\mathrm{Na}$ mesma linha de pesquisa, encontram-se os trabalhos de Lima $(2010)^{6}$, Cerezer (2010) ${ }^{7}$ e Amaral (2012) ${ }^{8}$ com essa ferramenta.

$\mathrm{Na}$ sequência, tratar-se-á dos fatores de atribuição na THA, dos procedimentos investigativos e da análise e discussão de resultados.

\section{OS FATORES DE ATRIBUIÇÃO NA TEORIA HOLÍSTICA DA ATIVIDADE}

Após introduzir-se o objetivo deste trabalho, no contexto da Teoria Holística da Atividade (THA), explicar-se-á como os Fatores de Atribuição apresentam-se em seu desenvolvimento.

Para tanto, parte-se do conceito de Atribuição segundo o viés richteriano (2011), a saber: um conjunto de variáveis centradas nas noções de papéis sociais, espaços institucionais (onde a atividade é exercida), atribuições (que tarefas são previstas), competências (em que bases curriculares e jurídicas a

\footnotetext{
${ }^{6}$ A pesquisadora analisou produções textuais em Língua Espanhola, apresentando dados estatísticos relacionados ao aumento de itens lexicais em textos acadêmicos, comparando-os ao final do primeiro e segundo semestres do Curso de Letras - habilitação Português/Espanhol.

7 A pesquisadora usou o MS para verificar o aumento de conectores em espanhol em produções de acadêmicos de Letras.

${ }^{8}$ A pesquisadora utilizou o MS para verificar estatisticamente as relações entre vocábulos que designam competência gnoseológica e praxeológica a fim de compreender como se constituíam as expectativas acerca do papel social em Letras e Educação Física.
} 
atividade é exercida), modelos de conduta (que padrões de comportamento são esperados, em seus devidos contextos, para o profissional, o cliente e demais pessoas), referência e pertença grupal.

Este metafator também responde por questões relativas à modelagem do papel social (identificação, introjeção e acoplamento). Ele relaciona-se com a divisão de trabalho que cabe a cada um (profissional, cliente, terceiros paralelamente envolvidos) fazer, dizer, saber-crer, valorar, sentir, como e quando (RICHTER, 2008). Refere-se também ao processo identitário, ancorado na autoimagem social, o valor-prestígio de seu lugar, de suas práticas, do bem social que o cliente vem a obter em virtude da intervenção do profissional.

$\mathrm{Na}$ THA, o papel social docente pode ser observado em dois desdobramentos:

a) papel concebido como manifestação particular de um coletivo. $O$ sujeito fica reabsorvido no fator comunidade (profissional), realizando na prática o que, em termos de grupo, está pré-estipulado. Para Richter (2008), é o correlato semiótico intrasubjetivo de uma relação.

b) papel concebido como conjunto de atitudes-condutas frente ao cliente.

Richter (2008) aponta como o correlato semiótico intersubjetivo (físicoobjeto) de uma relação.

Para o autor, o conceito de identidade profissional está atrelado à organização contratual do trabalho, em termos de conduta de procedimentos, acrescida dos conceitos e esquemas norteadores, do conhecimento declarativo, procedural, conceptual e dos valores adotados, com sua respectiva hierarquização.

De acordo com Richter (2008, p. 54), vê-se:

a presença, nesse perfil, da dimensão constitutiva (apropriação de um papel por identificação), articulativa (discriminação entre as duas faces do papel) e exercitiva (tradução de um conjunto de competências em prestação eficaz de serviços na moldura de uma organização do trabalho pré-estabelecida).

Richter (2008) afirma que embora a profissionalização, ou a apropriação de um papel, dependa da interação entre a instrumentalidade extrínseca e intrínseca da linguagem, o aspecto operacional de internalização (conhecer, compreender, aceitar, assumir) do processo global, por suas propriedades de 
reflexo e refração de práticas sociais intersubjetivas e orientadas, pode ser acompanhado na dimensão intrínseca da instrumentalidade linguageira, a saber, relacionadas às propriedades discursivas da formação profissional.

Neste estudo, selecionaram-se as lexias professor e profissional na categoria nódulos-problema, relacionadas ao papel social que se deseja analisar quantitativamente. Já as lexias conhecimento e formação (contemplando a competência gnoseológica), didático, ensino e motivação (contemplando a competência praxeológica), os verbos modais deve (na categoria ordenamento), precisa (na categoria necessidade) e pode (na categoria possibilidade), como nódulos-vínculo.

Encerram-se as orientações teóricas sobre os fatores de atribuição com um quadro que contempla os parâmetros de investigação da THA Estendida, versão 3.0, elaborada por Richter (2011).

TEORIA HOLÍSTICA ESTENDIDA DA ATIVIDADE (THA ESTENDIDA) - VERSÃO 3.0

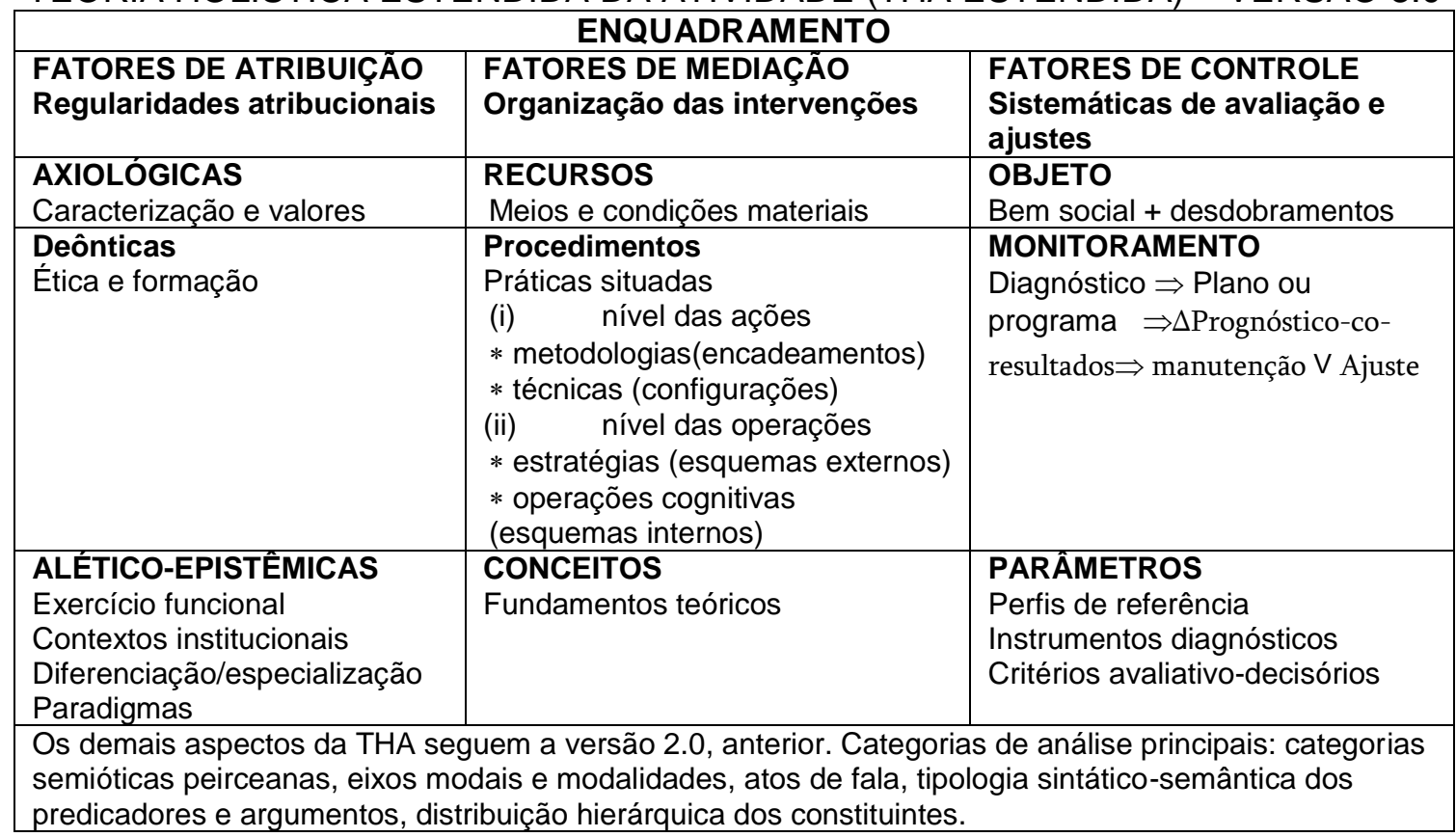

Quadro 1 - Esquema da THA Estendida (RICHTER, 2011). Reproduzido com permissão do autor.

A versão Estendida da THA apresenta os níveis de análise de linguagem relacionados às regularidades atribucionais axiológicas, referentes à caracterização e valores; deônticas, relacionadas à ética e à formação; aléticoepistêmicas, com referência ao exercício funcional, contextos institucionais, diferenciação/especialização e paradigmas. Essas regularidades atribucionais 
estão relacionadas às escolhas das lexias para a realização do mapeamento semântico.

Pela ordem crescente de complexidade, têm-se os fatores de atribuição, de mediação e de controle, que serão explicados sucintamente, conforme apresentado no quadro 1.

a) Por atribuição entende-se o conjunto de variáveis centradas nas noções de papéis sociais, espaços institucionais, atribuições, competências, modelos de conduta, referência e pertença grupal. Cabe também a este metafator responder pela modelagem do papel social quanto à identificação, introjeção e acoplamento.

b) A mediação é um metafator que, juntamente com o controle, responde pelos procedimentos profissionais. No caso do professor de línguas, a mediação engloba os fatores situacionais do ato linguodidático, enfatizando seus aspectos instrumentais e teleológicos, ao passo que 0 controle equaciona e monitora o estado decorrente do ato praticado, fornecendo o feedback para a manutenção, ajuste ou mudança das estratégias de intervenção. Os fatores de atribuição subdividem-se em recursos, estratégias e conceitos.

c) O objeto é conceitualmente dependente da natureza do ato profissional que nele incide. Ele é tripartido em: bem social (competência comunicativa), alvo (objetivos gerais), objetivos (que equivalem aos objetivos específicos de uma tarefa). O resultado refere-se ao diferencial de desenvolvimento linguístico. Por fim, a avaliação consiste no monitoramento constante da adequação entre intervenções profissionais e expectativas de êxito.

Nesta pesquisa, será focalizado o fator de atribuição quanto às interfaces profissionais, recategorizadas modalmente na versão estendida da THA (RICHTER, 2011). Isso ocorrerá através do levantamento quantitativo, proporcionado pelo Mapeador Semântico. O mapeamento será feito para fins semântico-conceituais, por meio de associações entre nódulos de interesse para além dos limites da frase.

Buscar-se-á contrapor duas profissões, a de Psicólogo, correntemente emancipada, e de professor de Letras, não emancipada, quanto ao nível de 
coesão semântica entre as lexias relacionadas à linguagem e profissionalização.

$\mathrm{Na}$ próxima seção, discorrer-se-á sobre as etapas metodológicas do trabalho.

\section{METODOLOGIA}

A escolha dos corpora de estudo levou em conta os objetivos desta pesquisa - investigar a coesão semântica entre as lexias relacionadas aos Fatores de Atribuição em textos acadêmicos de Letras e Psicologia, contrapondo os resultados quantitativos do mapeamento semântico dos textos acadêmicos de uma profissão emancipada com os de uma profissão não emancipada. A escolha pela área de Letras se deu em função da área de estudo e trabalho da pesquisadora ${ }^{9}$. Com relação à Psicologia, a escolha ocorreu, primeiramente, baseada pela regulamentação jurídica da carreira e, em segundo lugar, pelos Fatores de Atribuição dessa profissão apresentarem certa proximidade com os Fatores de Atribuição do educador linguístico.

Após a escolha das profissões, optamos por coletar os corpora via internet, em bibliotecas virtuais, e em bibliotecas de universidades de Santa Maria, tendo em vista a facilidade de acesso aos textos, disponibilizados ao domínio público.

A pesquisa online ocorreu por meio da visitação aos bancos de dados de bibliotecas de diferentes universidades brasileiras para realização dos downloads e formação dos corpora. $\mathrm{Na}$ visitação às universidades locais, a pesquisa foi realizada mediante consulta dos trabalhos acadêmicos digitalizados e disponibilizados para consulta.

Quanto à seleção dos textos, optou-se por textos acadêmicos das áreas selecionadas para o estudo, na categoria de trabalhos finais de graduação (TCCs), monografias (especialização lato sensu), dissertações e teses (especialização strito sensu) de profissionais de Letras e os mesmos gêneros discursivos para os profissionais da Psicologia. Esses textos apresentam um

\footnotetext{
${ }^{9}$ Professora do Instituto Federal Farroupilha, Campus São Vicente do Sul.
} 
número expressivo de palavras em relação aos demais textos acadêmicos, fator importante para a formação de bancos de dados e, por sua vez, dos corpora de estudo. Destaca-se que a seleção dos textos não se baseou em palavras-chave prévias para que não se direcionasse os resultados.

O interesse dessa pesquisa não visava selecionar apenas os estudos acadêmicos que abordassem diretamente o perfil profissional docente de ambas as profissões. $O$ interesse deste estudo era trazer à tona como os profissionais de Letras e Psicologia, de uma forma geral, utilizam a linguagem para tratar de questões referentes às lexias selecionadas como nódulosproblema e vínculo, sem que o foco do estudo fosse centralizado na figura do profissional da linguagem ou do profissional da psicologia.

A formação desses corpora era tentar verificar estatisticamente as relações entre os nódulos-problema e vínculo que designam o papel social do profissional de Letras e Psicologia, à luz dos pressupostos teóricos da THA.

A escolha pelo discurso acadêmico e científico se deu devido à forma de apresentação da linguagem que circula na comunidade científica, considerando que sua formulação depende de uma pesquisa minuciosa e efetiva sobre um objeto, que é metodologicamente analisado à luz de uma teoria, além da extensão e número de palavras que esses textos apresentam.

Reforça-se que a intenção é verificar como os Fatores de Atribuição, a partir da THA, estão inseridos neste discurso, observando as competências Gnoseológica e Praxeológica ${ }^{10}$ (RICHTER, 2011) dos profissionais envolvidos nesta pesquisa.

Assim, coletaram-se os corpora e separaram-se os textos da área de Letras em dois grupos, em função da assimetria interna do sistema ao qual pertencem (alopoiético): a) TCCs e monografias lato sensu, relacionadas aos profissionais de mercado; b) dissertações e teses, relacionadas aos profissionais da academia.

Quanto aos profissionais da área da Psicologia, profissão regulamentada e regida autopoieticamente, optou-se por um único corpus devido à indistinção entre os profissionais graduados e pós-graduados no mercado de trabalho desta área. Isso se deve ao fato de que o profissional da área da Psicologia

\footnotetext{
${ }^{10}$ Informação obtida em seção de orientação (2011).
} 
termina a graduação pronto para atuar no mercado de trabalho, com um perfil profissional definido pelo Conselho Federal de Psicologia, sem exigência de uma formação continuada ou especialização para o exercício da profissão.

No total, foram 381 arquivos de TCCs e monografias lato sensu de Letras, 219 arquivos de teses e dissertações de Letras e 321 arquivos de TCCs, monografias, dissertações e teses de Psicologia.

Os corpora apresentam os seguintes dados numéricos, determinados pelo tamanho do arquivo quanto ao número de palavras:

a) TCCs e monografias lato sensu de Letras com 15.766.364,00 dados no total; 2.425.141,00 tokens (running words) e 2.425.141,00 tokens usados na WordList.

b) dissertações e teses de Letras com cerca de 46.948.056,00 dados no total; com 7.045.330,00 tokens (running words) e 7045.332,00 de tokens usados na WordList.

c) no corpus de Psicologia, tem-se $18.291 .920,00$ dados no total; 2.776.347,00 de tokens (running words) e 2.776.348,00 tokens usados na WordList.

Observa-se que o corpus de estudo pode se afigurar como um corpus de dimensão média, segundo terminologia proposta por Berber Sardinha (2000, p. 326).

\subsection{O MAPEADOR SEMÂNTICO DE RICHTER E BERBER SARDINHA}

O mapeador semântico (MS) foi criado por Richter e Berber Sardinha (2009) durante os estudos de Richter de pós-doutoramento no LAEL-PUCSP.

Segundo Richter (2011), a ferramenta surgiu para preencher uma lacuna do programa WordSmith Tools para fins semântico-conceituais, associações entre nódulos de interesse para além dos limites da frase e das janelas à esquerda e à direita que o Concord apresenta sobre as lexias pesquisadas.

De acordo com os autores, o objetivo do Mapeador Semântico é comparar cotextos de palavras selecionadas, localizando, identificando, quantificando e totalizando os colocados coincidentes (links), exceto palavras por ignorar. 
Os resultados são exibidos na forma de um arquivo texto com as informações distribuídas conforme os itens abaixo:

nódulos.txt. as palavras pesquisadas

results_left.txt.comparação dos contextos à esquerda

results_left_right.txt: comparação dos contextos à esquerda com os da direita

results_position_by_position.txt. comparação de posição a posição

results_right.txt. comparação dos contextos à direita

results_right_left.text: comparação dos contextos à direita com os da esquerda

stopwords.tmp: palavras para ignorar

FIGURA 1: Exemplo de resultados exibidos pelo MS.

A figura 1 mostra os resultados fornecidos pelo programa; trata-se de uma amostra do mapeamento com nódulos. Os resultados, gerados pelo MS, foram inseridos no programa Word.

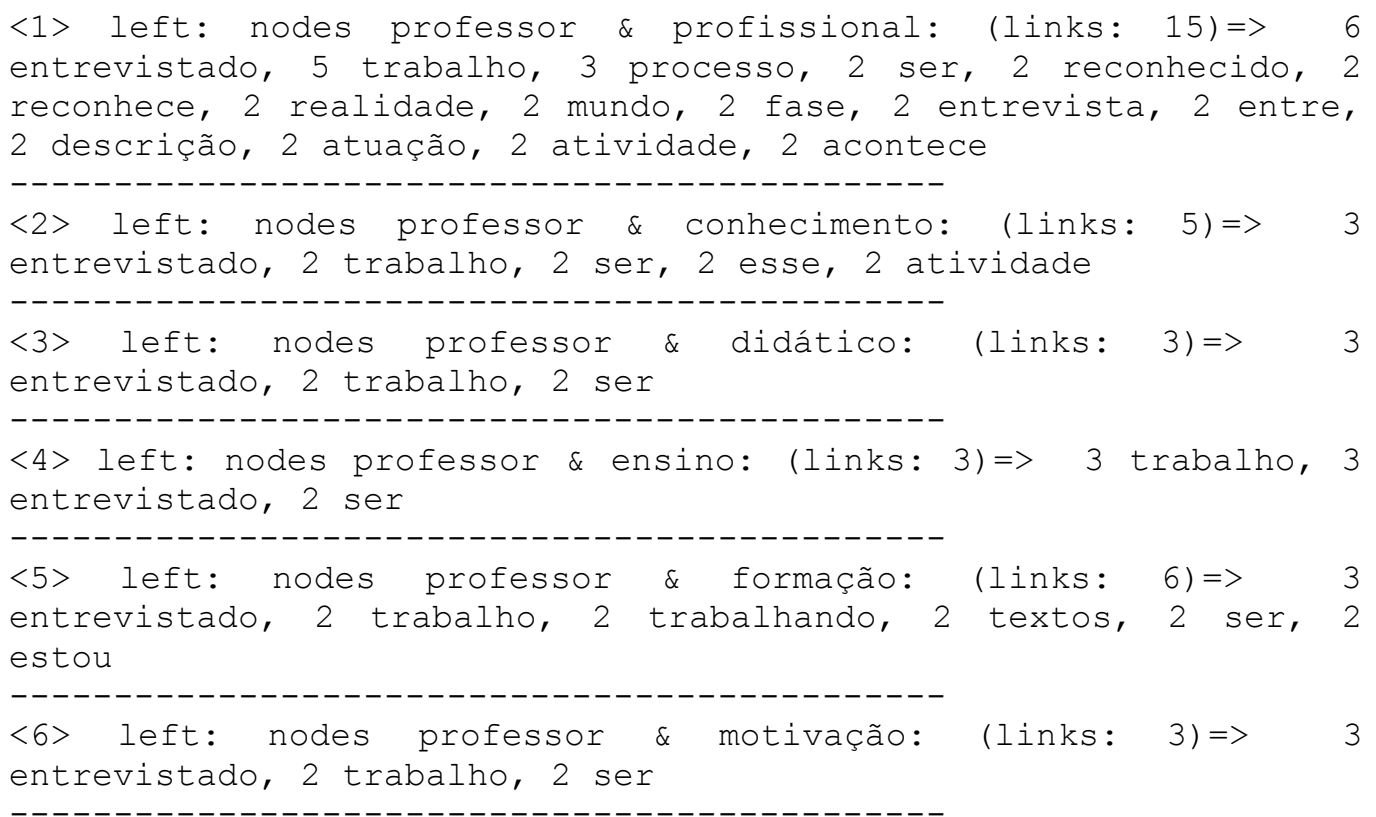

Figura 1 - Amostra dos resultados do MS.

Na página do MS, encontra-se uma explicação sobre a usabilidade do programa quanto à análise qualitativa e quantitativa das interconexões dos cotextos. O MS coloca à disposição do usuário informações sobre o 
comportamento em rede semântica dos nódulos de interesse da pesquisa, as quais podem ser utilizadas qualitativa e/ou quantitativamente para elucidar questões acerca das associações semânticas das palavras (e das respectivas forças associativas), a fim de auxiliar o mapeamento conceitual do corpus.

Para utilização do MS, o usuário deve fazer um upload do corpus que pretende analisar. Após o envio do corpus, o programa gera um código para ser inserido nos dados de identificação. Depois do preenchimento dos campos de identificação, basta clicar em rodar o programa e aguardar o link de resultados.

Richter (2011, p.126) acrescenta que:

(I) para toda palavra há um cotexto de $n$ palavras; (II) que, em cada ocorrência de uma palavra, ela cotextualiza $n$ outras palavras; (III) que palavras com afinidade semântica coocorrem (por compartilharem schemas) e/ou tendem a apresentar cotextos ou partes de cotextos em comum, o programa inspeciona a janela de colocados à direita e à esquerda dos nódulos de interesse do pesquisador (ignorando os colocados pré-listados como irrelevantes), e identifica-quantifica os casos de cotextualidade lexical (RICHTER, 2011, p. 126).

Dessa forma, o MS busca a presença de colocados em comum das palavras de interesse determinadas pelo pesquisador, estabelecendo ligações entre os colocados, a fim de apresentar os nódulos de interesse em rede.

A partir dos resultados gerados pelo programa, o pesquisador pode interpretá-los da seguinte forma: as quantificações indicam a maior ou menor intensidade das relações entre um e outro item lexical (nódulo), verificando estatisticamente as associações entre eles.

Esta ferramenta já foi utilizada na pesquisa de Lima $(2010)^{11}$, Cerezer (2010) ${ }^{12}$ e Amaral (2012) ${ }^{13}$ e contribuirá para complementação dos resultados gerados pelo programa WordSmith Tools 6.0, nesta pesquisa.

11 Para maiores informações, consultar a dissertação disponível em: http://cascavel.cpd.ufsm.br/tede/tde_busca/arquivo.php?codArquivo=3488

A pesquisadora analisou produções textuais em Língua Espanhola, apresentando dados estatísticos relacionados ao aumento de itens lexicais em textos acadêmicos, comparando-os ao final do primeiro e segundo semestres do Curso de Letras - Habilitação Português/Espanhol.

12 Para maiores informações, consultar a dissertação disponível em: http://cascavel.cpd.ufsm.br/tede/tde_busca/arquivo.php?codArquivo=3488 
O MS está disponível gratuitamente online no seguinte endereço eletrônico http://www.corpuslg.org/tools/mapeamento. $\quad \mathrm{O}$ objetivo e $\quad$ a funcionalidade do programa estão disponíveis no site da página e já foram apresentados anteriormente.

Os textos devem estar em um só arquivo em formato txt (texto sem formatação). Após o envio, o programa gera um código numérico que é a chave para acessar e fazer os mapeamentos do corpus enviado. Esse código tem validade de uma semana; expirado este período, o usuário deve repetir o procedimento novamente.

Os dados produzidos pelo MS devem ser colocados em uma tabela para a realização do cálculo da Razão Vinculativa Nodular Comparada (RVNC).

A RVNC fornece a medida da coesão semântica entre as categorias nodulares. O cálculo é realizado da seguinte forma: somam-se os valores, dessa forma, obtém-se a média; divide-se o valor menor pelo maior, originando um índice de força associativa semântica comparativa, que vai de zero a um (0 a 1).

Os resultados do mapeamento adquirem sentido quando analisados à luz de uma teoria, nesta pesquisa a THA. A interpretação é feita contabilizandose o número da divisão; "um número baixo, entre 0,1 e 0,5, indica que a relação entre os nódulos é relativamente frágil ou baixa; já um valor alto de 0,5 a 1, sugere aproximação entre as forças associativas dos nódulos-problema e nódulos-vínculo" (AMARAL, 2012, p. 81).

$\mathrm{Na}$ próxima seção, exemplificar-se-á a aplicabilidade do mapeador semântico para este estudo.

\footnotetext{
A pesquisadora utilizou o MS para verificar o aumento de conectores em espanhol em produções de acadêmicos de Letras.

13 Para maiores informações, consultar a dissertação disponível em: http://cascavel.cpd.ufsm.br/tede/tde_busca/arquivo.php?codArquivo=????

A pesquisadora utilizou o MS para verificar estatisticamente as relações entre os vocábulos que designavam competência gnoseológica e praxeológica a fim de compreender como se constituía as expectativas acerca do papel social em duas áreas, Letras e Educação Física.
} 


\section{ANÁLISE E DISCUSSÃO DOS RESULTADOS DO MAPEAMENTO SEMÂNTICO DOS NÓDULOS DE ESTUDO}

Nesta seção, será feita a análise do mapeamento semântico das lexias professor, profissional, conhecimento, didática, motivação, ensino, precisa, deve e pode dos três corpora da pesquisa.

\subsection{MAPEAMENTO DO CORPUS DE TCCS E MONOGRAFIAS LATO}

\section{SENSU DE LETRAS}

Após a investigação das frequências do nódulos-problema em relação aos nódulos-vínculo de TCCs e Monografias lato sensu de Letras, apresentamse os resultados no Quadro 2.

\begin{tabular}{|c|c|c|c|c|c|}
\hline Categoria & Subcategoria & $\begin{array}{l}\text { Nódulo } \\
\text { vínculo }\end{array}$ & $\begin{array}{l}\text { Posição } \\
\text { relativa }\end{array}$ & $\begin{array}{l}\text { Nódulo } \\
\text { problema } \\
\text { A/professor }\end{array}$ & $\begin{array}{l}\text { Nódulo } \\
\text { problema } \\
\text { B/profissional }\end{array}$ \\
\hline \multirow{28}{*}{$\begin{array}{l}\text { Atribuição } \\
\text { Papel } \\
\text { Social }\end{array}$} & \multirow{14}{*}{$\begin{array}{l}\text { Competência } \\
\text { Gnoseológica } \\
\text { (RICHTER, 2011) }\end{array}$} & \multirow[t]{7}{*}{ Conhecimento } & Left & 1147 & 630 \\
\hline & & & Left-Right & 1167 & 654 \\
\hline & & & Right & 1230 & 667 \\
\hline & & & Right-Left & 1208 & 639 \\
\hline & & & TOTAL & 4752 & 2590 \\
\hline & & & MÉDIA & 1.188 & 647.5 \\
\hline & & & $\begin{array}{l}\text { Razão } \\
\text { Vinculativa } \\
\text { B/A }\end{array}$ & \multicolumn{2}{|c|}{0,54} \\
\hline & & \multirow[t]{7}{*}{ Formação } & Left & 1053 & 526 \\
\hline & & & Left-Right & 1036 & 484 \\
\hline & & & Right & 1095 & 517 \\
\hline & & & Right-Left & 1137 & 540 \\
\hline & & & TOTAL & 4321 & 2067 \\
\hline & & & MÉDIA & 1080.25 & 516.7 \\
\hline & & & $\begin{array}{l}\text { Razão } \\
\text { Vinculativa } \\
\text { B/A }\end{array}$ & \multicolumn{2}{|c|}{0,47} \\
\hline & \multirow{14}{*}{$\begin{array}{l}\text { Conhecimento } \\
\text { Praxeológico } \\
\text { (RICHTER, 2011) }\end{array}$} & \multirow[t]{7}{*}{ Didático } & Left & 786 & 241 \\
\hline & & & Left-Right & 824 & 267 \\
\hline & & & Right & 893 & 285 \\
\hline & & & Right-Left & 869 & 257 \\
\hline & & & TOTAL & 3372 & 1050 \\
\hline & & & Média & 843 & 262.5 \\
\hline & & & $\begin{array}{l}\text { Razão } \\
\text { Vinculativa } \\
\text { B/A }\end{array}$ & \multicolumn{2}{|c|}{0.31} \\
\hline & & \multirow[t]{7}{*}{ Ensino } & Left & 1457 & 958 \\
\hline & & & Left-Right & 1358 & 851 \\
\hline & & & Right & 1508 & 864 \\
\hline & & & Right-Left & 1385 & 984 \\
\hline & & & TOTAL & 5708 & 3657 \\
\hline & & & MÉDIA & 1427 & 914.25 \\
\hline & & & Razão & \multicolumn{2}{|c|}{0.64} \\
\hline
\end{tabular}




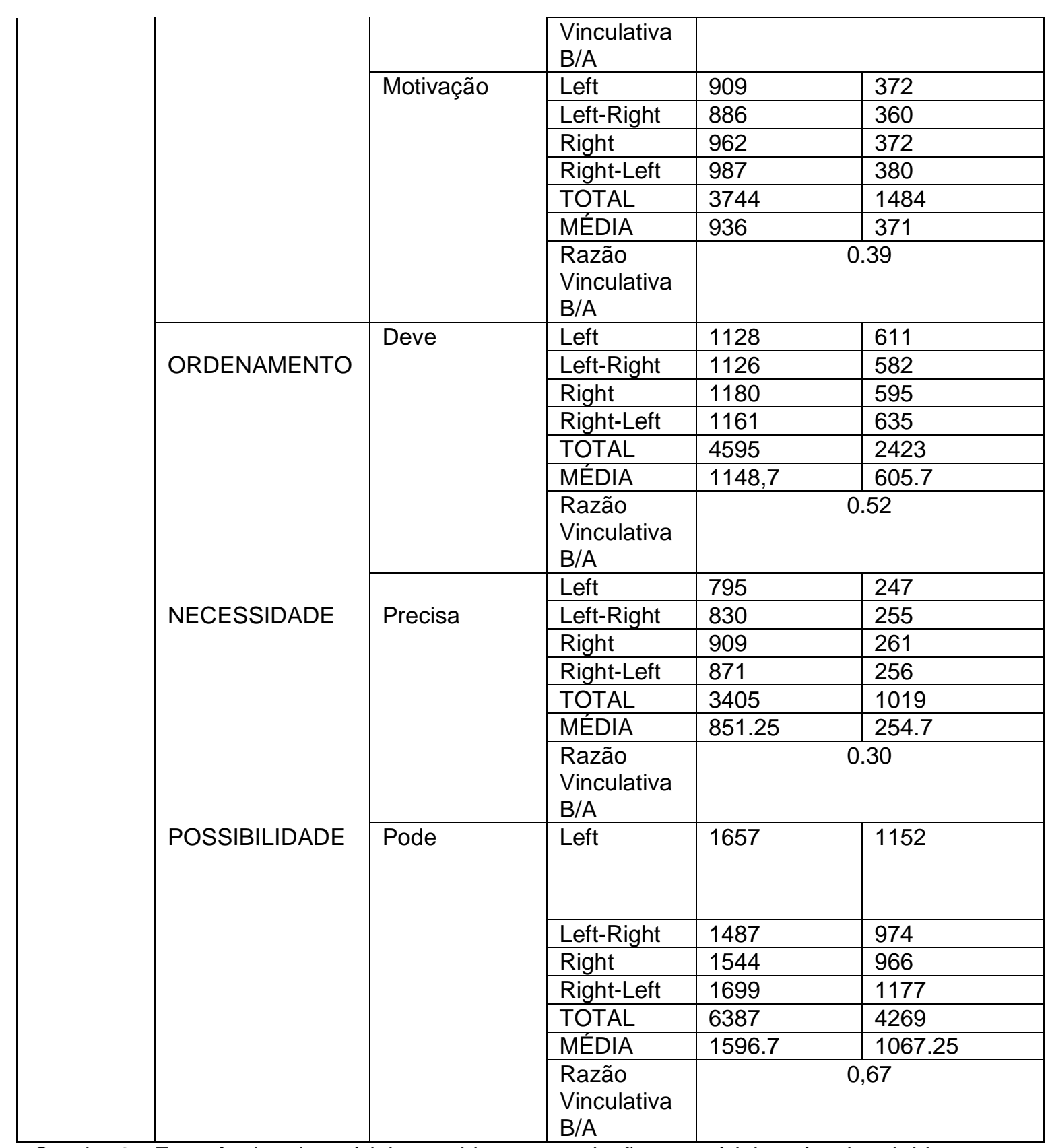

Quadro 2 - Frequências dos nódulos-problema em relação aos nódulos-vínculo, obtidas com o Mapeador Semântico - Corpus de TCCs e Monografias lato sensu de Letras. (Fonte: Frequências dos nódulos-problema em relação aos nódulos-vínculo, obtidas com o Mapeador Semântico - Corpus de TCCs e Monografias lato sensu de Letras)

Pode-se verificar que as relações entre os nódulos é relativamente baixa, pois os resultados do cálculo da RVNC ficaram entre 0,3 e 0,67.

Observa-se que algumas lexias apresentam maiores relações com os nódulos-problema do que outras. Por exemplo, a lexia conhecimento obteve 0,54 como resultado da RVNC, valor acima de 0,5. Essa lexia faz parte das atribuições do profissional, de acordo com os fatores de atribuição da THA e 
parece fazer parte das preocupações dos autores do corpus, referente aos profissionais de mercado.

Já as lexias formação $(0,47)$, didático $(0,31)$, motivação $(0,39)$ e precisa $(0,30)$ não obtiveram um valor significativo no cálculo da RVNC. Isso significa que para os profissionais de mercado o enquadramento referente às questões de formação (deônticas) e procedurais (práticas situadas no nível das ações, como metodologias e técnicas, e no nível das operações, como estratégias e operações cognitivas) não estão no foco das preocupações profissionais.

Em contrapartida, as lexias ensino $(0,64)$, os modalizadores deve $(0,52)$ e pode $(0,67)$ obtiveram resultados acima de 0,5 . Isso demonstra que quanto ao enquadramento dos Fatores de Atribuição, na subcategoria da competência gnoseológica, o conhecimento é uma questão que faz parte do interesse de pesquisa dos profissionais dessa categoria.

Já no enquadramento dos Fatores de Atribuição, referente às regularidades atribucionais, visualiza-se, por meio do resultado quantitativo, que questões como formação (deônticas), conforme explicitadas no Quadro 1 sobre os Fatores de Atribuição na versão estendida da THA, são relativamente significativas para estes profissionais.

Na sequência, será apresentado um recorte do mapeamento com a lexia profissional. 


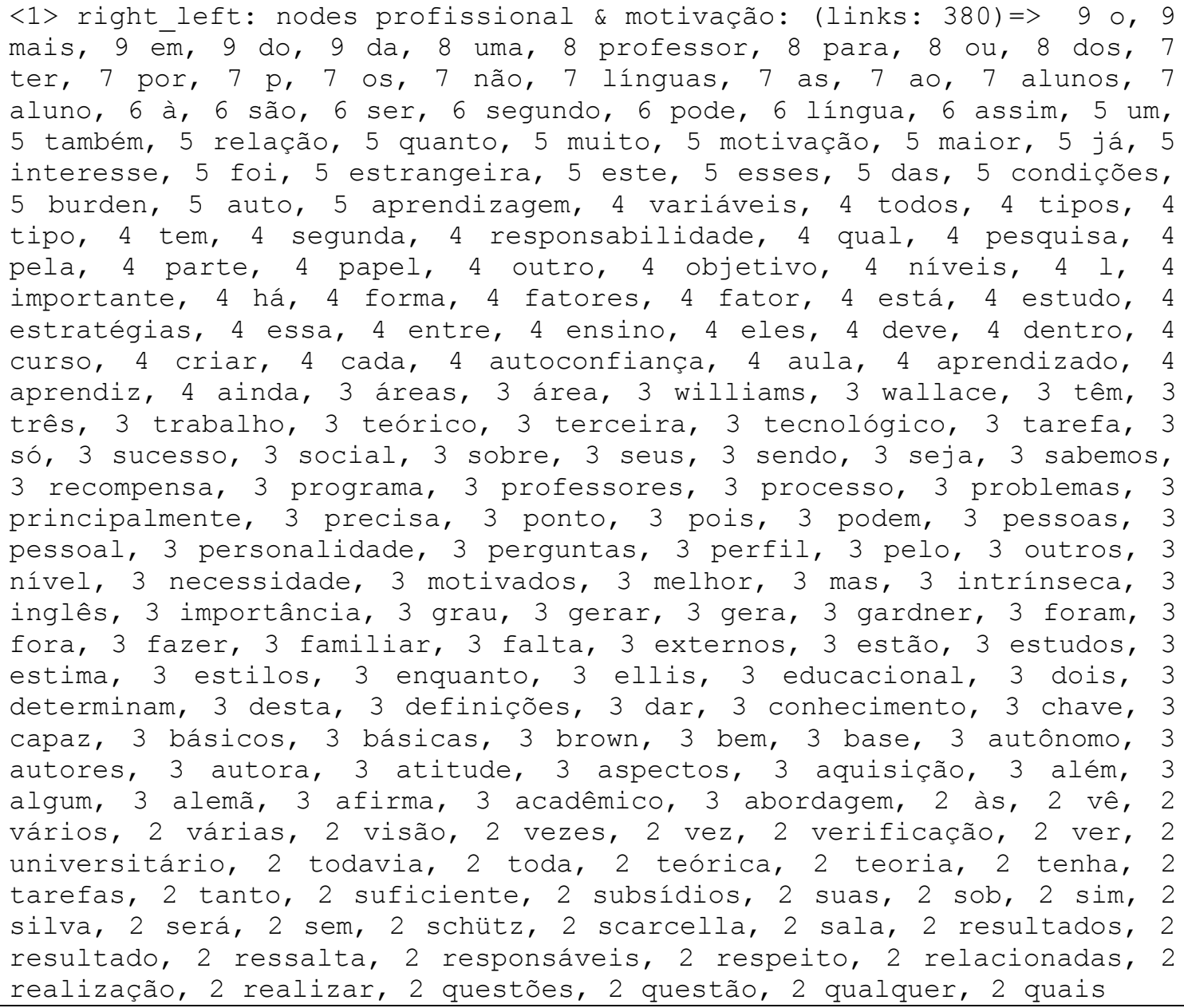

Quadro 3 - Mapeamento com a lexia profissional TCCs e Monografias lato sensu de Letras.

Este resultado foi gerado pelo MS e serve como exemplo do que foi realizado com todas as outras lexias. Como afirmado anteriormente, o cálculo é realizado somando-se os valores, que resultam em uma média. Na sequência, divide-se o valor menor pelo maior, originando um índice de força associativa semântica comparativa, que vai de zero a um ( 0 a 1$)$.

Na sequência, os resultados foram inseridos no Quadro 1, conforme já explicitado.

\subsection{MAPEAMENTO DO CORPUS DE DISSERTAÇÕES E TESES DE}

\section{LETRAS}

Após a investigação das frequências do nódulos-problema em relação aos nódulos-vínculo de Dissertações e Teses de Letras. , apresentam-se os resultados no Quadro 4. 


\begin{tabular}{|c|c|c|c|c|c|}
\hline Categoria & Subcategoria & $\begin{array}{l}\text { Nódulo } \\
\text { vínculo }\end{array}$ & $\begin{array}{l}\text { Posição } \\
\text { relativa }\end{array}$ & $\begin{array}{l}\text { Nódulo } \\
\text { problema } \\
\text { A/professor }\end{array}$ & $\begin{array}{l}\text { Nódulo } \\
\text { problema } \\
\text { B/profissional }\end{array}$ \\
\hline \multirow{42}{*}{$\begin{array}{l}\text { Atribuição } \\
\text { Papel } \\
\text { Social }\end{array}$} & \multirow{14}{*}{$\begin{array}{l}\text { Competência } \\
\text { Gnoseológica } \\
\text { (RICHTER, } \\
\text { 2011) }\end{array}$} & \multirow{7}{*}{ Conhecimento } & Left & 3230 & 2078 \\
\hline & & & Left-right & 3304 & 2164 \\
\hline & & & Right & 3505 & 2226 \\
\hline & & & Right/left & 3517 & 2156 \\
\hline & & & TOTAL & 13556 & 7624 \\
\hline & & & MÉDIA & 3389 & 1906 \\
\hline & & & $\begin{array}{l}\text { Razão } \\
\text { vinculativa } \\
\text { B/A }\end{array}$ & &, 56 \\
\hline & & \multirow[t]{7}{*}{ Formação } & Left & 2948 & 1752 \\
\hline & & & Left-right & 2848 & 1571 \\
\hline & & & Right & 3127 & 1676 \\
\hline & & & Right-left & 3244 & 1805 \\
\hline & & & TOTAL & 12167 & 6804 \\
\hline & & & MÉDIA & 3041.7 & 1701 \\
\hline & & & $\begin{array}{l}\text { Razão } \\
\text { vinculativa } \\
\text { B/A }\end{array}$ & &, 56 \\
\hline & \multirow{21}{*}{$\begin{array}{l}\text { Conhecimento } \\
\text { Praxeológico } \\
\text { (RICHTER, } \\
2011 \text { ) }\end{array}$} & \multirow[t]{7}{*}{ Didático } & Left & 2247 & 799 \\
\hline & & & Left-right & 2852 & 922 \\
\hline & & & Right & 2675 & 1059 \\
\hline & & & Right-left & 2597 & 945 \\
\hline & & & TOTAL & 10371 & 3725 \\
\hline & & & Média & 2592.7 & 931.25 \\
\hline & & & $\begin{array}{l}\text { Razão } \\
\text { Vinculativa } \\
\text { B/A }\end{array}$ & & ,36 \\
\hline & & \multirow[t]{7}{*}{ Ensino } & Left & 3208 & 2055 \\
\hline & & & Left-right & 3301 & 2113 \\
\hline & & & Right & 3489 & 2169 \\
\hline & & & Right-left & 3484 & 2144 \\
\hline & & & TOTAL & 13482 & 8481 \\
\hline & & & MÉDIA & 3370.5 & 2120.25 \\
\hline & & & $\begin{array}{l}\text { Razão } \\
\text { vinculativa } \\
\text { B/A }\end{array}$ & & .63 \\
\hline & & \multirow[t]{7}{*}{ Motivação } & Left & 2163 & 672 \\
\hline & & & Left-right & 2155 & 670 \\
\hline & & & Right & 2518 & 829 \\
\hline & & & Right-left & 2525 & 825 \\
\hline & & & TOTAL & 9361 & 2996 \\
\hline & & & MÉDIA & 2340 & 749 \\
\hline & & & $\begin{array}{l}\text { Razão } \\
\text { vinculativa } \\
\text { B/A }\end{array}$ & & 32 \\
\hline & \multirow[t]{7}{*}{ Ordenamento } & \multirow[t]{7}{*}{ Deve } & Left & 2772 & 1484 \\
\hline & & & Left-right & 2759 & 1391 \\
\hline & & & Right & 3059 & 1543 \\
\hline & & & Right-left & 3071 & 1623 \\
\hline & & & TOTAL & 11661 & 6041 \\
\hline & & & MÉDIA & 2915.25 & 1510.25 \\
\hline & & & $\begin{array}{l}\text { Razão } \\
\text { vinculativa }\end{array}$ & & .51 \\
\hline
\end{tabular}




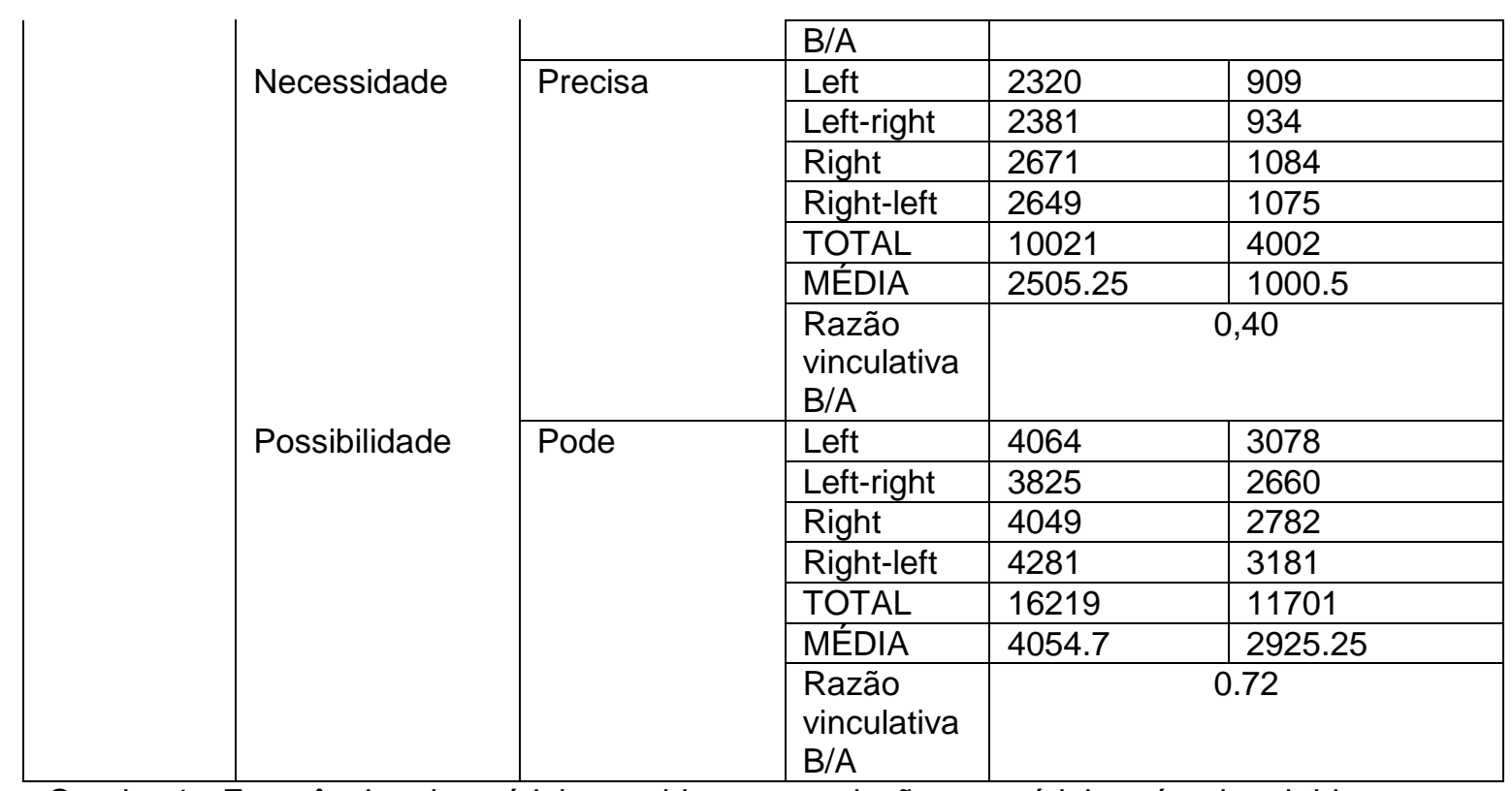

Quadro 4 - Frequências dos nódulos-problema em relação aos nódulos-vínculo, obtidas com o Mapeador Semântico - Corpus de dissertações e teses de Letras. (Fonte: Frequências dos nódulos-problema em relação aos nódulos-vínculo, obtidas com o Mapeador Semântico Corpus de dissertações e teses de Letras).

Novamente os resultados da RVNC são relativamente baixos, ou seja, entre 0,32 e 0,72. As lexias que apresentaram um resultado mais baixo foram didático $(0,36)$, motivação $(0,32)$ e precisa $(0,40)$. Das três, duas, didático e motivação, relacionadas com a subcategoria da competência praxeológica, apresentam resultados muito abaixo de 1,0.

Já o modalizador precisa, referente aos Fatores de Atribuição que designam necessidade, não é enfocado por este grupo, preponderando apenas os verbos deve $(0,51)$ e pode $(0,72)$. Esses verbos deônticos apresentam uma frequência maior e um resultado mais elevado da RVNC. Esta categoria de profissionais estaria mais próxima da endogenia, conforme demonstram os resultados quantitativos da RVNC, pois empregam com significativa frequência formas deônticas que, segundo os Fatores de Atribuição da THA, estão mais voltados para a ética e formação profissional.

Ainda se tem um resultado aproximado nas lexias conhecimento $(0,56)$, formação $(0,56)$ e ensino $(0,63)$. Estas estariam relacionadas tanto com os Fatores de Atribuição referentes às questões axiológicas (caracterização e valores) quanto às alético-epistêmicas, referentes ao exercício funcional (especialização e paradigmas). Elas estariam voltadas para as questões de 
ordenamento e possibilidade, considerando as subcategorias estabelecidas para a análise do mapeamento semântico.

A seguir, será apresentado um recorte do mapeamento com a lexia profissional.

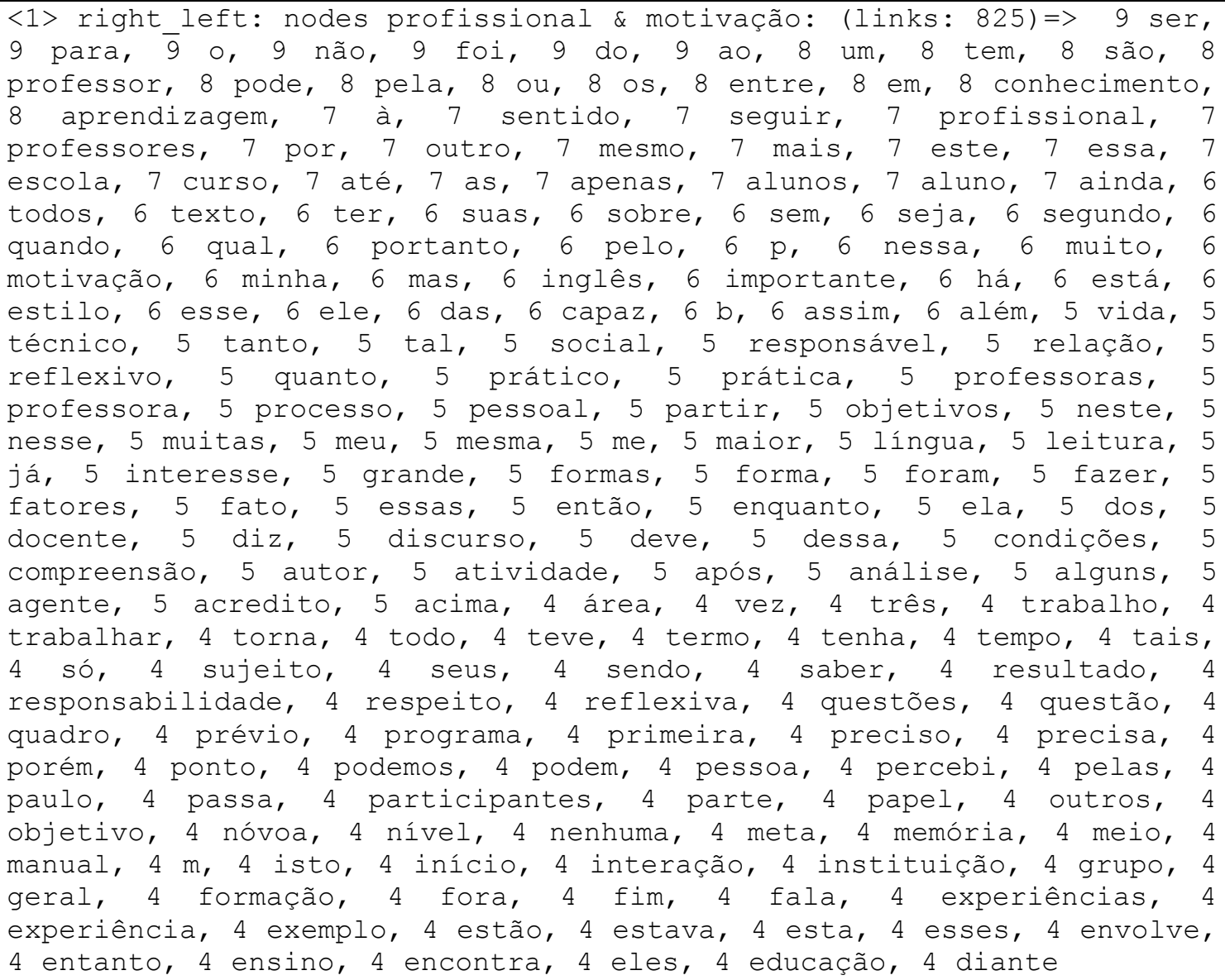

Quadro 5 - Mapeamento com a lexia profissional em dissertações e teses.

O exemplo do mapeamento com a lexia profissional no corpus 2 apresenta resultados numéricos diferentes do corpus anterior. Os valores dos links foram calculados conforme a explicação anterior e inseridos no quadro 4 para análise qualitativa.

4.3 MAPEAMENTO DO CORPUS DE TCCS, MONOGRAFIAS LATO SENSU, DISSERTAÇÕES E TESES DE PSICOLOGIA

Nesta fase, os resultados obtidos foram:

\begin{tabular}{|l|l|l|l|l|l|} 
Categoria & Subcategoria & Nódulo & Posição & Nódulo & Nódulo
\end{tabular}




\begin{tabular}{|c|c|c|c|c|c|}
\hline & & vínculo & relativa & $\begin{array}{l}\text { problema } \\
\text { A/professor }\end{array}$ & $\begin{array}{c}\text { problema } \\
\text { B/profissional }\end{array}$ \\
\hline \multirow{49}{*}{$\begin{array}{l}\text { Atribuição } \\
\text { Papel } \\
\text { social }\end{array}$} & \multirow{14}{*}{$\begin{array}{l}\text { Competência } \\
\text { Gnoseológica } \\
\text { (RICHTER, } \\
\text { 2011) }\end{array}$} & \multirow[t]{7}{*}{ Conhecimento } & Left & 745 & 1006 \\
\hline & & & Left-right & 778 & 1020 \\
\hline & & & Right & 828 & 1095 \\
\hline & & & Right/left & 795 & 1110 \\
\hline & & & TOTAL & 3146 & 4231 \\
\hline & & & MÉDIA & 786.5 & 1057.7 \\
\hline & & & $\begin{array}{l}\text { Razão } \\
\text { vinculativa B/A }\end{array}$ & & 0,74 \\
\hline & & \multirow[t]{7}{*}{ Formação } & Left & 673 & 922 \\
\hline & & & Left-right & 677 & 887 \\
\hline & & & Right & 734 & 1018 \\
\hline & & & Right-left & 715 & 1021 \\
\hline & & & TOTAL & 2799 & 3848 \\
\hline & & & MÉDIA & 699.75 & 962 \\
\hline & & & $\begin{array}{l}\text { Razão } \\
\text { vinculativa B/A }\end{array}$ & & 0,72 \\
\hline & \multirow{21}{*}{$\begin{array}{l}\text { Conhecimento } \\
\text { Praxeológico } \\
\text { (RICHTER, } \\
\text { 2011) }\end{array}$} & \multirow[t]{7}{*}{ Didático } & Left & 285 & 546 \\
\hline & & & Left-right & 279 & 553 \\
\hline & & & Right & 307 & 664 \\
\hline & & & Right-left & 308 & 671 \\
\hline & & & TOTAL & 1179 & 2434 \\
\hline & & & Média & 294.7 & 608.5 \\
\hline & & & $\begin{array}{l}\text { Razão } \\
\text { vinculativa B/A }\end{array}$ & & 0,48 \\
\hline & & \multirow{7}{*}{ Ensino } & Left & 564 & 814 \\
\hline & & & Left-right & 550 & 815 \\
\hline & & & Right & 594 & 908 \\
\hline & & & Right-left & 586 & 931 \\
\hline & & & TOTAL & 2294 & 3468 \\
\hline & & & MÉDIA & 573.5 & 867 \\
\hline & & & $\begin{array}{l}\text { Razão } \\
\text { vinculativa B/A }\end{array}$ & & 0,66 \\
\hline & & \multirow[t]{7}{*}{ Motivação } & Left & 520 & 773 \\
\hline & & & Left-right & 518 & 775 \\
\hline & & & Right & 555 & 867 \\
\hline & & & Right-left & 575 & 890 \\
\hline & & & TOTAL & 2688 & 3305 \\
\hline & & & MÉDIA & 672 & 826.25 \\
\hline & & & $\begin{array}{l}\text { Razão } \\
\text { vinculativa B/A }\end{array}$ & & 0,81 \\
\hline & \multirow[t]{7}{*}{ Ordenamento } & \multirow[t]{7}{*}{ Deve } & Left & 965 & 1187 \\
\hline & & & Left-right & 923 & 1138 \\
\hline & & & Right & 957 & 1256 \\
\hline & & & Right-left & 1009 & 1311 \\
\hline & & & TOTAL & 3854 & 4892 \\
\hline & & & MÉDIA & 963.5 & 1223 \\
\hline & & & $\begin{array}{l}\text { Razão } \\
\text { vinculativa B/A }\end{array}$ & & 0,78 \\
\hline & \multirow[t]{7}{*}{ Necessidade } & \multirow[t]{7}{*}{ Precisa } & Left & 502 & 775 \\
\hline & & & Left-right & 534 & 774 \\
\hline & & & Right & 566 & 882 \\
\hline & & & Right-left & 534 & 877 \\
\hline & & & TOTAL & 2136 & 3308 \\
\hline & & & MEDIA & 534 & 827 \\
\hline & & & Razão & & 0,64 \\
\hline
\end{tabular}




\begin{tabular}{|c|c|c|c|c|}
\hline \multirow{8}{*}{ Possibilidade } & \multirow{8}{*}{ Pode } & \multirow{2}{*}{$\begin{array}{l}\text { vinculativa B/A } \\
\text { Left }\end{array}$} & \multirow[b]{2}{*}{2032} & \multirow[b]{2}{*}{2194} \\
\hline & & & & \\
\hline & & Left-right & 1724 & 1937 \\
\hline & & Right & 1774 & 1989 \\
\hline & & Right-left & 2078 & 2294 \\
\hline & & TOTAL & 7608 & 8414 \\
\hline & & MÉDIA & 1902 & 2103.5 \\
\hline & & $\begin{array}{l}\text { Razão } \\
\text { vinculativa B/A }\end{array}$ & & 0,9 \\
\hline
\end{tabular}

Quadro 6 - Frequências dos nódulos-problema em relação aos nódulos-vínculo, obtidas con Mapeador Semântico - Corpus de TCCs e Monografias lato sensu, dissertações e teses Psicologia. (Fonte: Frequências dos nódulos-problema em relação aos nódulos-vínculo, obtidas c - Mapeador Semântico - Corpus de TCCs e Monografias lato sensu, dissertações e teses Psicologia.)

Obtiveram-se resultados diferentes dos da pesquisa prévia sobre o fator de atribuição de Amaral (2012), talvez por se trabalhar com corpora diferentes e maiores. O mapeamento revelaíndices altos (1,0 ou acima de 0,3$)$ de associações entre palavras (RVNC), no corpus de Psicologia. Este resultado pode ter ocorrido porque a Psicologia é uma profissão regulamentada, com um conselho de ética que normatiza o agir profissional que transparece no discurso de seus profissionais.

Neste corpus, o resultado das RVNCs demonstrou que os valores foram maiores para a lexia pode $(0,9)$ e deve $(0,78)$, referente aos fatores de atribuição das práticas deônticas, envolvendo questões de ética e formação. Em segundo lugar, aparece a lexia motivação $(0,81)$ que não obteve resultado significativo nos outros dois corpora. Ela estaria relacionada à subcategoria da competência praxeológica, envolvendo regularidades atribucionais mais axiológicas, de cunho mais relacional e/ou interacional. Já em terceiro lugar, estão as lexias conhecimento $(0,74)$ e formação $(0,72)$, pertencentes à subcategoria da competência gnoseológica. Pode-se dizer que elas caracterizam o discurso endogenamente organizado deste grupo de profissionais.

Com valores mais baixos, aparecem as lexias ensino $(0,66)$, precisa $(0,64)$ e didático $(0,48)$. Dos três, os dois primeiros apresentariam um valor significativo de relação semântica com os nódulos-problema: o primeiro relacionado à competência praxeológica e o segundo com a necessidade, ambos relacionados aos Fatores Atribucionais de enquadramento previstos pela THA. Vale a pena ressaltar que os profissionais da Psicologia só não 
apresentaram um resultado significativo no mapeamento semântico da lexia didático $(0,48)$.

Finaliza-se esta etapa da análise observando que esta categoria de profissionais apresenta resultados quantitativos mais elevados das lexias relacionadas ao campo de pesquisa da linguagem e profissionalização se comparada aos resultados da RVNC dos outros dois corpora do estudo.

$\mathrm{Na}$ sequência, apresenta-se um recorte do mapeamento com a lexia profissional.

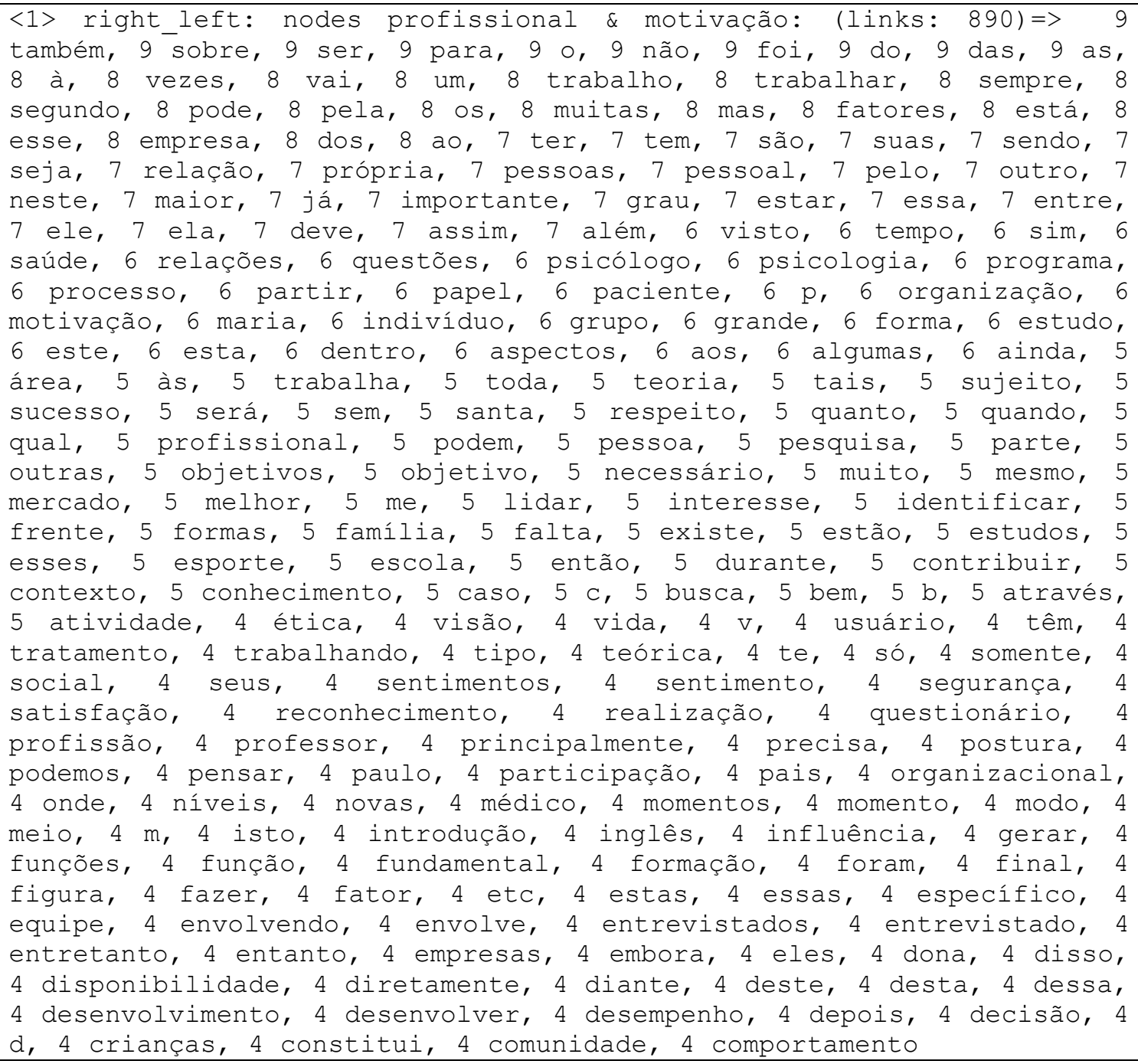

Quadro 7 - Mapeamento com a lexia profissional em Psicologia.

Este mapeamento também apresenta resultados diferentes do corpus anterior. Os resultados deste mapeamento também foram inseridos em um quadro (Quadro 6) para posterior análise qualitativa. 


\section{CONSIDERAÇÕES FINAIS}

Os resultados gerados pelo MS demonstram que os profissionais da área de Letras, que pertencem à categoria de profissionais de mercado, apresentaram resultados significativos na relação semântica nodular com as lexias ensino $(0,64)$, relacionada ao conhecimento praxeológico e pode $(0,67)$, relacionada à possibilidade. Isso denota que os profissionais dessa área e categoria estão mais preocupados com a prática docente e o que se pode fazer em termos de docência.

Tal resultado pode ser associado à escassa categorização da experiência laboral (RICHTER, 2011), pois provavelmente refletem uma preocupação com a prática desvinculada da teoria. Essa constatação pode ser confirmada pelo resultado que as lexias conhecimento e formação obtiveram no mapeamento.

Também o corpus com os textos acadêmicos de profissionais da área de Letras, categorizados como profissionais da academia, obteve resultados similares com as lexias ensino e pode. Estas considerações projetam adequação acentuada das expectativas às circunstâncias singulares, embora essa categoria de profissionais esteja mais ciente do hermetismo lexical e teórico da área, bem como uma noção da tipificação da norma e do desvio, e uma concepção mais finalística do trabalho. Já o corpus da área da Psicologia apresentou resultados bem diferentes, muito provavelmente por ser uma profissão juridicamente regulamentada e por seguir a orientação de trabalho e formação do psicólogo a partir do que designa o Conselho Federal de Psicologia (CFP).

Os resultados do mapeamento obtiveram destaque em quase todas as subcategorias. Por esta razão, denotam que estes profissionais orientam-se por expectativas mais normativas, típico de atividades regulamentadas. Esses dados da pesquisa permitem constatar que os psicólogos apresentam uma concepção mais finalística do trabalho, um diferencial normativo endógeno, acentuada categorização da experiência laboral e atitude deôntica da prática. 
A pesquisa possibilitou uma diferenciação entre duas profissões, uma regulamentada e outra não regulamentada, a partir das relações semânticas entre os nódulos de interesse, acarretando o desejo de que o educador linguístico possa buscar meios para a regulamentação de sua profissão. Também demonstrou que os textos acadêmicos de Letras necessitam estabelecer uma coesão semântica maior, especificamente entre as lexias que designam linguagem e profissionalização. Isso possibilitaria a construção de um discurso mais endógeno e autopoiético, próximo das profissões regulamentadas.

\section{REFERÊNCIAS}

AMARAL, J. Relatos da docência em textos de revista: expectativa, papel social e emancipação, um estudo comparativo entre letras e educação física, 2012. 124p. Dissertação (Mestrado em Letras) Universidade Federal de Santa Maria, Santa Maria, 2012.

BERBER SARDINHA, T. B. Linguística de Corpus: histórico e problemática. Revista Delta. São Paulo, v. 16, n. 2. 2000.

CEREZER, A. Aquisição dos conectores escritos em língua espanhola por acadêmicos do curso de letras segundo a teoria holística da atividade. 2010. 151p. Dissertação (Mestrado em Letras) Universidade Federal de Santa Maria, Santa Maria, 2010.

Lei de diretrizes e bases da educação nacional. Disponível em: portal.mec.gov.br/arquivos/pdf/ldb.pdf

LIMA, L. J. R. DE. Aquisição do léxico em espanhol como língua estrangeira segundo a teoria holística da atividade. 2010. 173p. Dissertação. (Mestrado em Letras) Universidade Federal de Santa Maria, santa Maria, 2010.

MAPEADOR SEMÂNTICO. Disponível em <http://corpus.orgqtools/mapeament o/> Richter e Sardinha, 2009. Acesso em: 02 de junho de 2011.

Resolução do CFP - Conselho Federal de Psicologia - No 010/2005. Disp. :http://WWW.apsp.org.br/a_orien/código/fr_codigo_etica_indice_new.htm 
RICHTER, M.G.; GARCIA, J.R. C. A profissionalização do professor no cenário legislativo existente. In: Linguagens \& Cidadania, № 12, jul-dez 2004. Disponível em: www.ufsm. br/linguagem_e_cidadania . Aquisição, Representação e Atividade. Santa Maria, RS: UFSM/PPGLEditores, 2008, Série Cogitare, vol. 6. . Saberes didáticos: em favor do ensino ou da aprendizagem? In: IX ENCONTRO DO CELSUL, 9., 2010, Palhoça, SC. Anais eletrônicos. Palhoça: Universidade do Sul de Santa Catarina, 2010. v. 9, 11p. Disponível em: http://www.celsul.org.br/encontros09/artigosqmarcos\%20richter.pdf. Acesso em: 30 set. 2010.

. Profissionalização docente segundo a teoria holística da atividade: estudo empregando software de mapeamento semântico. In: Linguagem e interação: o ensino em pauta. ALBUQUERQUE, R.; MOTTA, V. A. (Orgs.). São Paulo: Pedro e João, 2011. 